\section{Behavioral Consultation and Primary Care: A Guide to Integrating Services, Second Edition}

Patricia J. Robinson and Jeffrey T. Reiter

Cham, Switzerland, Springer International Publishing, 2016, 347 pp., \$79.99, hardcover

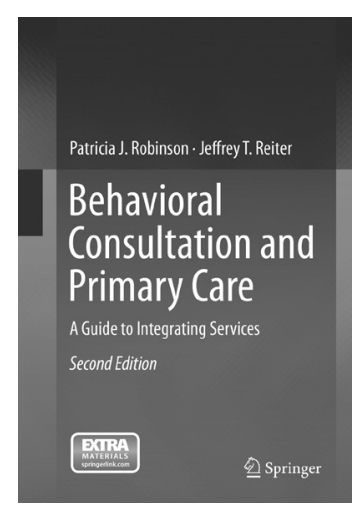

From introducing the concept of the Primary Care Behavioral Health (PCBH) model, to practical evaluative and practice tools, this text serves as a helpful handbook of implementation of integration. It provides valuable resources for administrators, primary care providers (PCP), behavioral health consultants (BHC) and support staff. The authors begin by presenting a compelling discussion of the ways in which integration increases provider, staff, and patient satisfaction while improving overall quality of care and health of populations served. The PCBH model presented in this book is one in which the BHC works as a consultant to the PCP and a member of the care team, rather than a colocated therapist.

Behavioral health integration has been an interest of mine for several years. In my previous leadership role at a community health center, before having the chance to read this book, I had the responsibility of leading the implementation of an integrated behavioral health program. The path was bumpy and at times trying. I found that this text addresses many of the challenges we faced with practical solutions.

Robinson and Reiter have organized the book into five parts with 15 chapters. Each chapter concludes with a helpful summary and relevant web links. In addition to the physical textbook, the authors have placed supplemental materials online and have linked these materials to relevant passages in the book.

Part I introduces the reader to the concept of behavioral health in the context of primary care and the benefits of integration to PCPs, BHCs, support staff, individual patients and to the health of the population. Part I emphasizes that while behavioral health integration can be beneficial in many ways and can be implemented in a financially sustainable way, the PCBH model will not be highly profitable monetarily. In my past experience, I found that getting buy-in for integration from key stakeholders was sometimes time consuming and difficult. This chapter shares vital information in a concise way that could be referenced to help obtain this buy-in, and could help save time and effort for the implementation team.

Part II provides important guidance on building the behavioral health team with specific tools to aide in designing, training, and evaluating the integration. This section includes a discussion about the importance of including behavioral health documentation in the general medical record and not in a separate location as is done in traditional mental health models. The last section of Part II discusses the important role of training PCPs and RNs to effectively work with the BHCs to truly transform the practice.

Part III shares information on the practice of behavioral health care. This part is especially helpful for the PCP who is new to integration. Part III explains the differences between and the benefits of the medical model and behavioral health models of addressing health. Rather than eliminate illness as the medical model aims to do, the behavioral health model broadly helps patients positively adapt to changes in the context of health and the context of their lives in general. Working through the basic concepts of various therapeutic approaches within the behavioral health model, the authors give a helpful resource to PCPs who may otherwise be unfamiliar with these concepts. The last chapter of Part III provides useful metrics for assessing the quality and effectiveness of the program within the health center and in the context of population health.

Part IV provides detailed descriptions of day-to-day activities for a BHC and gives examples of how the day of a BHC can be used most effectively. The authors share tools that the $\mathrm{BHC}$ can use to introduce the model and 
even a checklist of activities for a new $\mathrm{BHC}$ to complete in the first 4 weeks of initiating integrated care. From my experience in integration, effective use of the BHCs time was a difficult challenge, and is key to the sustainability of the model. I would have appreciated this detailed example to walk me through how it can be done well.

Part V features a helpful discussion of the issues and challenges that can arise with implementation of an integrated system, including a primer on the growing opioid abuse epidemic and the role of behavioral health in this issue.

In today's health care environment, PCP burnout has become an important issue that needs to be addressed, and the authors show throughout the book how the PCBH model can help to improve patient care and help to alleviate this growing issue.

doi: 10.22454/FamMed.2018.963706

\section{Shruti Varadarajan, MD}

Baylor College of Medicine Department of Family and Community Medicine

Houston, Texas

\section{Needless Suffering: How Society Fails Those With Chronic Pain}

David Nagel

Lebanon, NH, University Press of New England, 2016, 343 pp., \$15 paperback/ebook

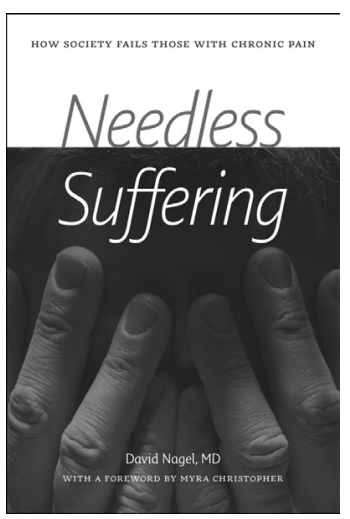

America has a pain problem. Estimates indicate 100 million people suffer from chronic pain. What is our way forward? Dr David Nagel, a 28-year veteran of treating pain, has written a comprehensive treatise on this subject. He gives the clearest account I have read of our country's on-again, off-again approach to pain management and how these pendulum swings have harmed patients. He covers everything from the politics of health care to our current dilemma of undertreating pain.

Each chapter begins with a quotation like this one from the Oath of Maimonides: "May I never see in the patient anything but a fellow creature in pain." ${ }^{\text {Dr Nagel makes it clear }}$ through statistics and anecdotes that patients with chronic pain have been mistreated. For example, too often learners witness role models talking about patients as "drug seekers" and then misapply this lesson. For that reason, this book should be read by medical students, residents, and clinicians to challenge them to thoughtfully treat those in pain.

Nagel offers clear recommendations for the system, medical education, and clinicians alike. Readers may be surprised to see a review of our health politics (his review of this subject is accurate and succinct), however, his analysis quickly reveals the trickle-down effect of such politics on pain patients. Without changes at a macro level, clinicians can't improve care of individuals. Late chapters give specific recommendations for office-based care. His ideas are classics, yet his emphasis is appreciated in this technologic era-listen to the patient, conduct a proper physical exam, communicate well with patients and team members. Don't expect to find an alternative approach to treating pain. The author reviews the evidence on herbs and supplements and rules against them. $\mathrm{He}$ is committed to proof; it is unfair to offer snake oil. His advice will resonate with those that know there are no shortcuts; treating chronic pain meaningfully requires commitment, teamwork, engaging family, and exercise.

Nagel does not mince words. Interventions have been overused without evidence of success. He strongly recommends the publication of more "negative results" studies. He writes that too many physicians have made money on the backs of patients' desperation. Patients need honesty-they will always have pain; there is no cure, only management. Realistic goals should be set focusing on function; this is done through tough love, self-awareness, and compassion. He advocates for a system with real rehabilitation putting people back to work in new jobs based upon evolving abilities. Opioids are often part of the plan and should be used with compassionate pain agreements, prescription monitoring systems, and toxicology screens. Cancer does not have a monopoly on opioids in his world. He also explores the promise of marijuana and encourages more studies.

The author has seen it all, and has powerful insights: patients fear losing their medications and lament their loss of being useful, while providers (somewhat inappropriately) fear losing their license. This is a terrible dichotomy. Nagel implores us to stop treating these patients like modern day lepers, making them 
jump through hoops to "prove" their pain. $\mathrm{He}$ provocatively challenges traditional notions; patients on opioids aren't addicted to opioids, they are addicted to pain relief! His lessons are clear: chronic pain is different from acute pain, and it is not a character flaw. He is sympathetic to patients. Likewise, he is sympathetic to clinicians. Their education has focused on cure, they have not been trained well in this topic, and they need more time and reimbursement.

My one criticism is that the book needs more editing. Some of the information early in the book is repeated in more detail later in the book. That being said, the reader will find the book an easy read because of the balance of evidence, stories, and opinions. Some readers may be put off by the mild religious undertone. He declares it up front. It does not undermine his message, and I found the quotations from the likes of Mother Theresa about caring for the least among us in our own backyards to be inspiring.

Dr Nagel is a rebel. He does not accept the status quo and challenges current medical models. He takes aim at the "business of medicine", the disability system, and the impersonal electronic health record. This is contrasted with affirmative recommendations about changing primary care training and incentives for treating chronic pain. His ideas about patient care will inspire readers to hold fast to concerns about our medical system and to advocate passionately for patients with chronic pain and other difficult-to-treat illnesses. I personally have adjusted my approach to treating chronic pain after reading this book. doi: 10.22454/FamMed.2018.841088

\section{Hugh Silk, MD, MPH}

University of Massachusetts Medical School Worcester, MA

\section{References}

1. Oath of Maimonides. Traditional oath attributed to Rabbi Moses ben Maimon (1135-1204 AD). Cited by: Nagel, David. Needless Suffering. Lebanon, NH: University Press of New England; 2016. p. 81

\section{Undoctored: Why Health Care Has Failed You and How You Can Become Smarter Than Your Doctor}

William Davis

New York, Rodale, 2017, 416 pp., \$19.39, hardcover

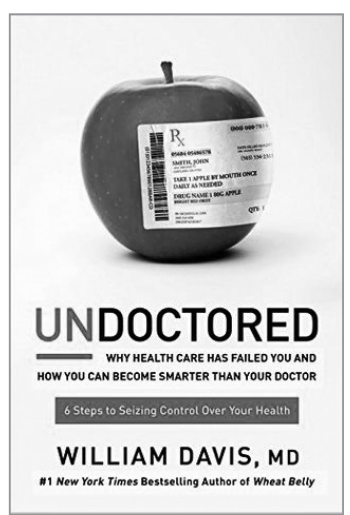

William Davis is a cardiologist and author of the Wheat Belly books. ${ }^{1,2}$ In Undoctored, Dr Davis takes the bold position that anyone can take control over their own health and go beyond the knowledge of most physicians. Medical care will still be necessary for accidents, major infections, or other life-threatening events. When it comes to prevention and managing chronic health problems, people will be better off with self-management and tapping into the wisdom of others.

Is this realistic? In 2009, I asked in a "Future Vision" article in Family Medicine, "Is Family Medicine Ready for Patient-Directed Care?"3 There is a growing movement toward self-directed care. Bill Gates has written, "The internet changes everything." ${ }^{\prime}$ The internet has radically changed most service industries except health care. Patients continue to put up with inconveniences that are no longer tolerated in other industries and submit to a paternalistic model of care. I expected that to change much sooner. There is evidence that as Google and Amazon are getting involved with health care, we may be in for real transformation, and family medicine will be affected.

According to Davis, becoming undoctored is a three dimensional effort. The first is to use the latest information on healthy nutrition to achieve an optimally functioning body and mind. This means a diet free of grains and sweets that drive up blood sugar and cause inflammation. Dr Davis goes into detail as to what foods and supplements a person should consume, and his recommendations are scientific, but deviate from the food industryinfluenced standard diet recommendations. Limited coverage is given to other elements of a healthy lifestyle such as physical activity, stress management, restful sleep, social connectedness, and a purposeful life. Dr Davis points out that all these are aided by healthy nutrition. 
The second dimension to becoming undoctored is to use the internet to become highly knowledgeable in health and any chronic health problems a person might have. With the internet, anyone can become knowledgeable in what applies to them. Davis also sees the widespread use of health-related apps by patients for health care monitoring and treatments.

The third dimension to becoming undoctored is to harness the "wisdom of crowds" as described by James Surowiecki in his book by that name. ${ }^{5}$ Using websites such as PatientsLikeMe, people can use the knowledge and experience of many in similar circumstances and gain wisdom that will exceed even that of an expert in a medical condition.

How should we in family medicine respond to this challenge to our role and identity? We continue to train our residents in a "take charge" model of care. We have started to teach "shared decision making", but becoming undoctored goes way beyond that.

I suggest faculty and learners read this book and consider the possibilities openly. Our roles as family physicians include much coaching, advising and motivational counseling. Having a patient take charge of their health is a good thing. I do not see becoming undoctored as a real threat because, as the adage goes, any physician who treats himself or herself has a fool for a patient. People need people to make good choices even when they have all the information. It is hard to be objective with information when it comes to your own health.
I know William Davis personally and let him know I intended to write a book review. He quickly responded that his book did not apply to doctors like me, grounded in lifestyle medicine. He is rightfully angry with traditional medicine in America that remains largely ignorant about healthy nutrition. Too often doctors are quick to prescribe drugs or procedures when a change in diet or other lifestyle is all that is needed. People can avoid unnecessary and even harmful interventions by following the undoctored approach to their health. Read this book for its trove of health information, and ponder the undoctored perspective as patients become more assertive in their health care.

doi: 10.22454/FamMed.2018.945734

\section{Joseph E. Scherger, MD, MPH}

Eisenhower Medical Center

La Quinta, CA

\section{References}

1. Davis W. Wheat Belly. New York: Rodale; 2011.

2. Davis W. Wheat Belly Total Health. New York: Rodale; 2014.

3. Scherger JE. Future vision: is family medicine ready for patient-directed care? Fam Med. 2009;41(4):285-288.

4. Gates B. The Road Ahead. New York: Penguin Group; 1995

5. Surowiecki J. The Wisdom of Crowds: Why the Many Are Smarter Than the Few and How Collective Wisdom Shapes Business, Economies, Societies and Nations. New York: Random House; 2004.

Reviewers interested in writing reviews for publication should contact Book and Media Reviews Editor William E. Cayley, Jr, MD, at bcayley@yahoo.com.

Publishers who wish to submit books for possible inclusion in Family Medicine's book reviews section should send texts to Sam Grammer, Society of Teachers of Family Medicine, 11400 Tomahawk Creek Parkway, Suite 240, Leawood, KS 66211. fmjournal@stfm.org

All books reviewed in this column are available for purchase at amazon.com through the STFM portal at www.stfm.org/bookstore. 